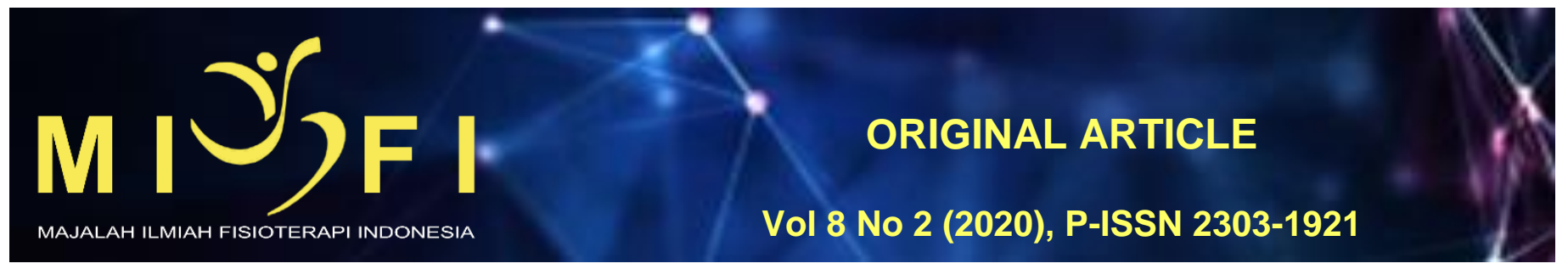

\title{
HUBUNGAN ANTARA INDEKS MASSA TUBUH (IMT) DENGAN RESIKO JATUH PADA LANSIA DI DENPASAR
}

\author{
Dwi Jayanti Pringgadani ${ }^{1}$, Ari Wibawa ${ }^{2}$, Nila Wahyuni ${ }^{3}$ \\ ${ }^{1}$ Program, Studi Sarjana Fisioterapi Dan Profesi Fisioterapi Universitas, Fakultas Kedokteran Universitas Udayana \\ ${ }^{2}$ Departemen Fisioterapi, Fakultas Kedokteran Universitas Udayana \\ ${ }^{3}$ Departemen Faal Fakultas Kedokteran Universitas Udayana
} dwijayantii30@gmail.com

\begin{abstract}
ABSTRAK
Indeks Massa Tubuh merupakan petunjuk untuk menentukan kelebihan berat badan berdasarkan Indeks Quatelet berat badan dalam kilogram dibagi dengan kuadrat tinggi badan dalam meter $(\mathrm{kg} / \mathrm{m} 2)$. IMT adalah cara termudah untuk memperkirakan obesitas serta berkorelasi tinggi dengan massa lemak tubuh. IMT yang tinggi mempunyai resiko jatuh lebih tinggi dibandingkan dengan IMT normal. Penelitian ini dilakukan pada bulan Desember 2018. Tujuan dalam penelitian ini untuk mengetahui hubungan antara indeks massa tubuh (IMT) dengan resiko jatuh pada lansia di Banjar Minggir. Penelitian ini menggunakan metode analitik cross sectional, pengambilan sampel dilakukan secara consecutive sampling sebanyak 41 orang. Hasil uji hipotesis menggunakan Spearman Rho didapat nilai $p<0,05$. Berdasarkan hasil penelitian tersebut maka dapat disimpulkan bahwa terdapat hubungan yang signifikan antara indeks massa tubuh (IMT) dengan resiko jatuh pada lansia di Banjar Minggir, Denpasar.
\end{abstract}

Kata Kunci: indeks massa tubuh (IMT), resiko jatuh, lansia

\section{THE RELATIONSHIP BETWEEN BODY MASS INDEX (BMI) AND THE RISK OF FALLS IN THE ELDERLY IN DENPASAR}

Body mass index is a clue to determine overweight based on Quatelet Index weight in kilograms divided by the square of height in metres $(\mathrm{kg} / \mathrm{m} 2)$. BMI is the easiest way to estimate obesity and correlated with high body fat mass. BMI has a high risk of falling higher than normal BMI. This research was conducted in December 2018. The purpose of this research is to know the relationship of body mass index (BMI) and the risk of falls in the elderly in Banjar Ming gir. This research use analytic methods cross sectional, sampling conducted in consecutive sampling of as many as 41 people. Hypothesis test results using the Spearman Rho obtained the value of $p<0.05 p$. Based on the results of the study it can be concluded that there is a significant relationship between body mass index (BMI) and the risk of falls in the elderly in Banjar Minggir, Denpasar.

Keywords: body mass index (BMI), risk of falls, elder 


\section{PENDAHULUAN}

Menurut World Health Organisation (WHO), lansia adalah seseorang yang telah memasuki usia 60 tahun keatas. Lansia merupakan kelompok umur pada manusia yang telah memasuki tahapan akhir dari fase kehidupannya. Jumlah lanjut usia (lansia) dari tahun ke tahun di Indonesia cenderung meningkat. Kantor Kementerian Koordinator Kesejahteraan Rakyat (KESRA) memperkirakan pada tahun 2020 perkiraan penduduk lansia di Indonesia mencapai 28,8 juta atau 11,34 \% dengan Usia Harapan Hidup sekitar 71,1 tahun (Kemensos, 2010).

Jumlah lansia yang terus meningkat, mendapat perhatian dari pemerintah yang ingin meningkatkan kualitas hidup lansia. Kualitas hidup lansia dicapai salah satunya dengan pencegahan masalah yang akan terjadi pada lansia. Jatuh merupakan salah satu masalah yang dihadapi lansia. Saat lansia jatuh akan terjadi penurunan kemandirian, meningkatnya biaya hidup lansia bahkan kematian, sehingga perlu ada usaha pencegahan jatuh dengan mengidentifikasi berbagai resiko jatuh pada lansia (Utami, 2015).

Satu dari tiga lansia yang berusia diatas 65 tahun mengalami jatuh tiap tahunnya. Diperkirakan 20\% sampai $30 \%$ lansia mengalami cidera sedang sampai cidera berat yang mengakibatkan gangguan dalam bermasyarakat. Pada tahun 2009 lebih dari 19,000 lansia meninggal karena jatuh dan menjadikan jatuh pada urutan ke lima yang mengakibatkan kematian pada lansia di atas 65 tahun (Felicia et al., 2013). Kira-kira sebanyak 25\% sampai 35\% lansia yang berusia 65 tahun atau lebih mempunyai mengalaman jatuh setiap tahunnya (Barak et al., 2014).

\section{METODE}

Desain penelitian ini adalah observasional dengan pendekatan cross sectional analitik yang telah dilakukan pada bulan Desember 2018 di Kelurahan Padang Sambian, Banjar Minggir, Denpasar. Penelitian ini telah disetujui oleh Komite Etik Penelitian Fakultas Kedokteran Udayana/Rumah Sakit Umum Pusat Sanglah Denpasar. Pengambilan sampel penelitian menggunakan teknik consecutive sampling. Jumlah total sampel penelitian ini sebanyak 41 orang dengan kriteria inklusi berusia antara 60-74 tahun, bersedia sebagai subjek penelitian dari awal sampai akhir penelitan, dan kriteria eksklusi dalam keadaan sakit.

Variabel independent pada penelitian ini adalah indeks massa tubuh (IMT), dan variabel tergantung adalah resiko jatuh. Sampel melakukan pengukuran IMT dengan mengukur tinggi badan dan berat badan. Setelah didapatkan hasil sampel akan melakukan pengukuran resiko jatuh menggunakan instrument Berg Balance Scale (BBS). Software statistika digunakan untuk melakukan analisis data. Analisis data yang digunakan yaitu analisis univariat, uji normalitas data menggunakan uji Kolmogorov Smirnov, dan analisis bivariat menggunakan uji Spearman Rho.

\section{HASIL}

Tabel 1. Karakteristik Sampel Berdasarkan Jenis Kelamin, Indeks Massa Tubuh (IMT), dan Resiko Jatuh

\begin{tabular}{|c|c|c|}
\hline Variabel & Frekuensi (n) & Persentase (\%) \\
\hline \multicolumn{3}{|c|}{ Jenis Kelamin } \\
\hline Laki-laki & 19 & $46,3 \%$ \\
\hline Perempuan & 22 & $53,7 \%$ \\
\hline \multicolumn{3}{|c|}{ Indeks Massa Tubuh (IMT) } \\
\hline Normal & 38 & $92,7 \%$ \\
\hline Tinggi & 3 & $7,3 \%$ \\
\hline \multicolumn{3}{|c|}{ Resiko Jatuh } \\
\hline Rendah & 24 & $53,5 \%$ \\
\hline Sedang & 14 & $34,1 \%$ \\
\hline Tinggi & 3 & $7,3 \%$ \\
\hline
\end{tabular}

Sampel dalam penelitian ini lebih banyak dari kalangan perempuan sebanyak 22 orang $(53,7 \%)$, dibandingkan dengan laki-laki sebanyak 19 orang $(46,3 \%)$. Sampel dalam penelitian ini terdapat 38 lansia $(92,7 \%)$ dalam kategori normal dan 3 lansia (7,3\%) dalam kategori overweightp. Sampel dalam penelitian ini terdapat 24 lansia (53,5\%) dalam kategori rendah, 14 lansia (34,1\%) dalam kategori sedang, dan 3 lansia $(7,3 \%)$ dalam kategori tinggip.

Gambar 1. Frekuensi Karakteristik Responden Berdasarkan UsiaSampel dalam penelitian yaitu di rentang usia 60 hingga 69 tahun dari sebaran paling banyak pada usia 65 tahun yaitu sekitar $26,8 \%$.

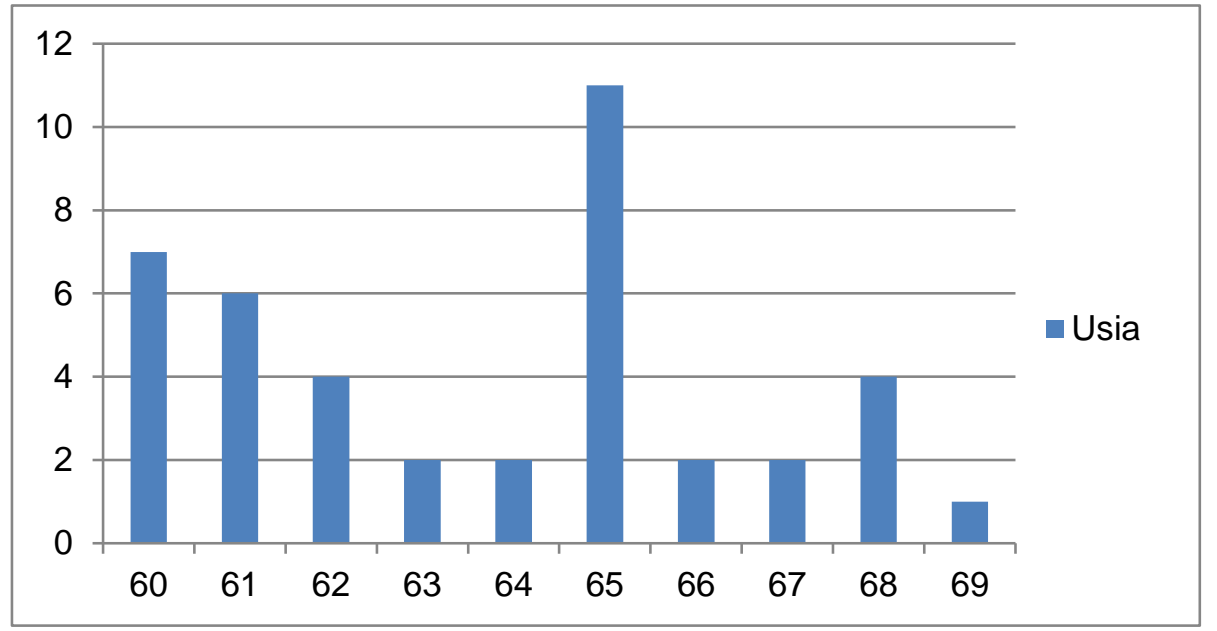




\begin{tabular}{c} 
Kolmogorov Smirnov \\
\hline Nilai $p$ \\
\hline 0,503
\end{tabular}

Uji Kolmogorov Smirnov untuk mengetahui kenormalan data yang diperoleh sebelum dilakukan dengan uji statistik sesuai dengan skala masing-masing variabel terlebih dahulup. Hasil uji Kolmogorov Smirnov didapatkan nilai signifikasi 0,503 > 0,05 maka dapat disimpulkan bahwa sampel berdistribusi normal.

Tabel 3. Hubungan IMT dengan Resiko Jatuh pada Lansia

\begin{tabular}{ccc}
\hline & $\begin{array}{c}\text { Resiko } \\
\text { Jatuh }\end{array}$ & \\
\hline & Nilai $p$ & $\begin{array}{l}\text { Correlation } \\
\text { Coefficient }\end{array}$ \\
\hline $\begin{array}{c}\text { Indeks } \\
\text { Massa } \\
\text { Tubuh }\end{array}$ & 0,01 & 0,01 \\
\hline
\end{tabular}

Untuk mengetahui adanya hubungan antara indeks massa tubuh (IMT) dengan resiko jatuh pada lansia di Banjar Minggir, Denpasar dilakukan uji korelasi bivariat dengan menggunakan teknik analisis data Spearman Rhop. Uji Spearman Rho adalah teknik yang digunakan untuk mengetahui hubungan antara dua variabelp. Hasil uji Spearman Rho didapatkan nilai $p=0,01 \quad(p<0,05)$, maka dapat disimpulkan bahwa Ho ditolak yaitu terdapat hubungan antara indeks massa tubuh (IMT) dengan resiko jatuh pada lanjut usia di Banjar Minggir, Denpasarp.

\section{DISKUSI}

\section{Karakteristik Responden}

Penelitian ini menggunakan responden lansia di Banjar Minggir, Denpasar yang berjumlah 41 orangp. Responden diambil menggunakan metode consecutive sampling di Banjar Minggir, Denpasar yang memenuhi kriteria inklusi dan eksklusi yang telah ditentukan. Adapun karakteristik sampel pada penelitian ini yang dilihat dari jenis kelamin dengan persentase $53,7 \%$ sampel perempuan lebih banyak dibandingkan dengan laki-laki yang hanya 46,3\%.

Persebaran usia responden menunjukkan bahwa rata-rata usia responden adalah usia lansia yaitu 60-69 tahun, dengan penyebaran usia sampel paling banyak di usia 65 tahun yaitu sebesar 26,8\%p. Sedangkan untuk sampel paling sedikit usia 69 tahun hanya 2,4\%. Responden dalam penelitian ini dapat dilihat bahwa usia 66-68 tahun memiliki nilai IMT yang tinggi sehingga masuk sebagai kategori overweight. Dengan tingginya IMT seseorang maka resiko jatuh yang dimiliki orang tersebut akan semakin tinggi dibandingkan dengan seseorang dengan nilai IMT yang normal. Data yang diperoleh dari 41 lansia atau responden di Banjar Minggir Denpasar, 3 lansia (7,3\%) memiliki nilai IMT tinggi dan 38 lansia (92,7\%) dikatakan normal.

Berdasarkan hasil penelitian di Banjar Minggir, Denpasar yaitu Indeks Massa Tubuh dari 41 responden lansia terdapat 38 lansia (92,7\%) dalam kategori normal dan 3 lansia $(7,3 \%)$ dalam kategori overweight. Obesitas merupakan kondisi yang dahulu dianggap sebagai lambang kesejahteraan. Akan tetapi, berkaitan dengan resiko kesehatan dan dampaknya terhadap kualitas hidup, kini obesitas merupakan problem kesehatan (Elvira, 2007). Prevalensi obesitas meningkat, baik di negara maju, maupun di negara berkembang. Di Eropa, prevalensinya berkisar $10-40 \%$ dalam 10 tahun terakhir (Suarca dan Suandi, 2007)p. Hasil riset terbaru dari Himpunan Studi Obesitas Indonesia (HISOBI) tahun 2004 dibandingkan dengan data Widya Karya Nasional Pangan dan Gizi (WKNPG) tahun 1998 menunjukkan peningkatan prevalensi obesitas pada pria dewasa 9,16\% dan wanita $11,02 \%$ (Lisbet, 2004).

Pada hasil penelitian resiko jatuh dari 41 responden lansia di Banjar Minggir, Denpasar tersebut terdapat 24 lansia $(58,5 \%)$ dalam kategori rendah, 14 lansia $(34,1 \%)$ dalam kategori sedang, dan 3 lansia $(7,3 \%)$ dalam kategori tinggip. Gangguan keseimbangan memiliki prevalensi yang cukup tinggi. Sekitar 85 persen pada lansia berumur lenih dari 60 tahun. Sebagai dampak gangguan keseimbangan dapat berupa peningkatan resiko jatuh dan kejadian jatuh berulang pada lansia yang dapat menyebabkan cedera ringan hingga berat dapat mempengaruhi aktifitas harian lansia serta kualitas hidup lansia (Hirvonen TP, et.all 1997 dalam Simoceli, Saraiva, Bittar, \& Sznifer, 2008). Hal tersebut bersesuaian dengan penelitian Shahanawaz (2015), dengan penurunan resiko jatuh dapat meningkatkan daily activity pada lansia. Serta penelitian Freira et al, (2015), lansia menunjukkan signifikansi peningkatan pada kualitas hidup lansia jika memiliki penurunan resiko jatuh.

\section{Hubungan Antara Indeks Massa Tubuh dengan Resiko Jatuh Pada Lansia di Banjar Minggir}

Pada perhitungan korelasi bivariat yaitu dengan uji analisis data Spearman Rho berdasarkan data diketahui bahwa nilai $n$ atau jumlah data penelitian sebanyak 41 responden, kemudia nilai $p=0,01 \quad(p<0,05)$ dapat disimpulkan bahwa ada hubungan antara indeks massa tubuh (IMT) dengan resiko jatuh pada lansia di Banjar Minggir Denpasar.

IMT dihitung sebagai berat badan dalam kilogram $(\mathrm{kg})$ dibagi tinggi badan dalam meter dikuadratkan $\left(\mathrm{m}^{2}\right)$ dan tidak terikat pada jenis kelamin. IMT secara signifikan berhubungan dengan kadar lemak tubuh total sehingga dapat dengan mudah mewakili kadar lemak tubuh. Saat ini, IMT secara internasional diterima sebagai alat untuk mengidentifikasi kelebihan berat badan dan obesitas (Hill, 2005). IMT adalah cara termudah untuk memperkirakan obesitas serta berkolerasi tinggi dengan massa lemak tubuh, selain itu juga penting untuk mengidentifikasi pasien obesitas yang mempunyai risiko komplikasi medis (Pudjiadi et al, 2010). Perubahan Indeks Massa Tubuh dapat terjadi pada berbagai kelompok usia dan jenis kelaminp. Indeks Massa Tubuh yang normal sangat diperlukan oleh semua orang untuk mempermudah melakukan aktivitas sehari-hari dan menghindari terjadinya penyakit (Gita, 2015). 
IMT yang tinggi mempunyai resiko jatuh lebih tinggi dibandingkan dengan IMT normal. IMT yang tinggi, terutama penumpukan lemak di abdominal mempunyai resiko mudah jatuh, hal ini terjadi karena seseorang yang mempunyai IMT tinggi, terjadi tekanan postural yang tinggi dan gangguan keseimbangan yang mengakibatkan berubahnya the center of the body mass (COM). Hal ini sangat dipengaruhi oleh instabilitas postural. Instabilitas postur sering dikaitkan dengan proses penuaan yang berhubungan dengan penurunan kekuatan otot, penurunan massa otot, penurunan kepadatan tulang, penurunan kualitas otot rangka, distribusi lemak (Corbeil et al., 2001).

Hasil penelitian ini sejalan dengan hasil penelitian sebelumnya yang telah dilakukan oleh Bhurtun (2012) didapatkan hasil adanya hubungan antara indeks massa tubuh (IMT) dengan resiko jatuh pada lansiap.

\section{SIMPULAN}

Berdasarkan tujuan dan hasil penelitian diatas, maka dapat disimpulkan bahwa ada hubungan yang signifikan antara Indeks Massa Tubuh (IMT) dengan resiko jatuh pada lansia di Banjar Minggir, Denpasar.

\section{DAFTAR PUSTAKA}

1. WHO. 2006. World Health Organization. [Online] Available at: http://apps.who.int/, [Accesed 20 Maret 2018 ]p.

2. Kementerian Sosial RI. 2010. Penduduk Lanjut Usia di Indonesia dan Masalah Kesejahteraannya. [Online] Available at: http://www.kemsos.go.id [Accesed 19 Maret 2018]p.

3. Utami, F. Y. (2015). Hubungan Indeks Massa Tubuh Dan Kecepatan Jalan Dengan Resiko Jatuh Pada Lanjut Usiap.

4. Felicia A. Geet P. and Jeffrey M. 2013. Risk Factors For Falls Among Older Adults: A Review Of The Literatur. Maturitas 75 (2013) 51-61p.

5. Barak Y, Robert C Wagenaar and Kenneth G Holt. 2014. Gait Characteristics of Elderly People With a History f Falls: A Dynamic Approach. J Am Geriatr Socp.

6. Elvira S.D, 2007. Penanganan Psikologik Pada Obesitas. Cermin Dunia Kedokteran. 34: 296-298p.

7. Suarca K, Suandi I.K.G, 2007. Hubungan Antara Total Lemak Tubuh dengan Profil Lipid Pada Anak Obese di SD Denpasar. Cermin Dunia Kedokteran. 34: 299-303p.

8. Lisbet C.A. 2004. Hubungan Antara Obesitas Berdasarkan Klasifikasi Indeks Massa Tubuh dengan Kejadian Sindroma Metabolik Pada Karyawan Bank. Nexus Medicus. 16:20-25p.

9. Hirvonen TP, Aalto H, Pyykko I, Juhola M, Jantti P. 1997. "Changes in Vestibulo-Ocular Reflex of Elderly People." Acta Otolaryingol Suppl (Stockh)p.

10. Shahanawaz SD1, Priyanshu. V.Rathod. 2015. "Effect of Vestibular Rehabilitation in Improving Daily Life Function in Elderlyp."

11. Freiria, Heloisa et al. 2015. "Effectiveness od a Vestibular Rehabilitation Protocol to Improve the Health-Related Quality of Life and Postural Balance in Patients with Vertigop."

12. Hill, J., 2006. Obesity: Etiology in Modern Nutrition in Health and Disease. [Online] Available at: http://www.itd.unair.ac.id [Accessed 19 Maret 2018]p.

13. Pudjiadi A, Hegar HB. 2010. Pedoman Pelayanan Medis Ikatan Dokter Anak Indonesia. Jakarta: IDAlp.

14. Gita Putu., Indah Sari., (2015). Hubungan Indeks Massa Tubuh (IMT) Dengan Keseimbangan Statis Pada Mahasiswa Fakultas Kedokteran Universitas Udayana. Majalah IImiah Fisioterapi Indonesia Volume 2 No $1 \mathrm{p}$.

15. Corbeil P. Simoneau M. and Rancourt D. 2001. Increased Risk For Falling Associated With Obesity: Mathematical Modeling Of Postural Control. IEEE Trans Neural Syst Rehabil Eng, 9:126-36p.

16. Bhurton H. 2012. Obesity As A Predictor Of Falls Among Older Women. Tesis. University of Jyväskyläp. 